\title{
Mental State of the Workers of the Ministry of Higher Education and Scientific Research (MESRS) in Benin in 2018
}

\author{
Gansou Grégoire Magloire ${ }^{1, ~ *, ~ E g a n h o u i ~ D e n i s ², ~ K l i k p o ~ E l v y r e ', ~}$ \\ Gnansounnou Glele Alda Lidwine Ekoundayo ${ }^{3}$, Houessou Patrick Yélindo Dossou ${ }^{4}$ \\ ${ }^{1}$ Faculty of Health Sciences, University of Abomey-Calavi and National Hospital and University Center of Psychiatry, Cotonou, Benin \\ ${ }^{2}$ Ecole Doctorale Pluridisciplinaire-Espace Culture et Développement, University of Abomey-Calavi, Cotonou, Benin \\ ${ }^{3}$ Ministry of Higher Education and Scientific Research, Cotonou, Benin \\ ${ }^{4}$ Faculty of Arts, Human and Social Sciences, University of Abomey-Calavi, Cotonou, Benin
}

Email address:

gregansou@gmail.com (G. G. Magloire), denis.eganhoui@yahoo.fr (E. Denis), eklikpo@gmail.com (K. Elvyre), glalda@gmail.com (G. G. A. L. Ekoundayo), yelindopatrick@yahoo.fr (H. P. Y. Dossou)

*Corresponding author

\section{To cite this article:}

Gansou Grégoire Magloire, Eganhoui Denis, Klikpo Elvyre, Gnansounnou Glele Alda Lidwine Ekoundayo, Houessou Patrick Yélindo Dossou. Mental State of the Workers of the Ministry of Higher Education and Scientific Research (MESRS) in Benin in 2018. American Journal of Psychiatry and Neuroscience. Vol. 7, No. 4, 2019, pp. 142-146. doi: 10.11648/j.ajpn.20190704.18

Received: November 20, 2019; Accepted: December 12, 2019; Published: December 21, 2019

\begin{abstract}
The work environment is an environment at risk for the psychological well-being of workers. This research is conducted on a population of 348 workers from the Ministry of Higher Education and Scientific Research (MESRS) in Benin. It was a cross, descriptive study, with an analytical goal, with non-probabilistic sampling, and by convenience. The research tools were documentation, SATIN scales, interview and observation. The results processed and analyzed by the Excel software, and R show that the general health is poor in $14.7 \%$ of workers, average in $27.9 \%$, and good in $57.5 \%$. Psychological health is poor in $10.3 \%$, average in $18.1 \%$, and good in $71.6 \%$. Physical health is poor in $6.1 \%$ of workers, average in $24.4 \%$, and good in $69.6 \%$. Similarly, stress is bad for $13.5 \%$ of workers, average for $37.7 \%$, and good for $48.8 \%$. Psychosomatic symptoms are poor in $19.6 \%$ of workers, average in $21.1 \%$ and $59.2 \%$. The symptoms are poor in $31.0 \%$ of workers, average in $16.5 \%$, and good in $52.5 \%$. The well-being of this population is attributable to several factors, the predominant element of which is the organizational environment and its conditions. Better consideration of the factors that strengthen human capital is essential for the physical and psychological well-being of MESRS workers.
\end{abstract}

Keywords: Mental State, MESRS Workers, Psychological Distress, Benin

\section{Introduction}

The professional world is nowadays under enormous risks, thus threatening its psychological well-being. Paine's "princeps" study estimated that the cost of the 23 million executives who suffered burnout in 1970 was in the range of $\$ 10$ to $\$ 20$ billion a year [1]. Leiter and Maslach [2] put this estimate at \$ 300 billion, incorporating sick leave, long-term incapacity for work and staff turnover. The International Labor Office (ILO) [3] estimated, in 1993, that stress had become one of the most serious health problems of our time.
In addition, stress, moral harassment, burn-out are frequently mentioned as risk factors for health, detrimental generators are frequently mentioned as risk factors for health, generators of psychological distress, leading to mental pathologies. Psychosocial risks come from the interaction of the individual (the psychological) and the work environment (the social), thus committing the responsibility of the company [4]. Stress costs between 3 and $4 \%$ of GDP in the European Union (OECD, 2012) [5]. The publications of the European Agency 
for Safety and Health at Work, carried out by the European Risk Observatory [6], show that the situation is not very good for the Member States, USA, Canada, Australia, Switzerland, and France where six categories of psychosocial risk factors were identified (work demands, emotional demands, lack of autonomy, lack of recognition, conflict of values, job insecurity).

In Benin, work accidents and professional illnesses have not been the subject of much study. The injuries caused are most often causes of absolute disability, partial or permanent and disability of the victim. Then, the indicators of safety and health at work in the Republic of Benin presented by Raouf Pereira at the WASHEQ in 2015 [7], shows that the statistics on industrial accidents and professional illnesses, in the Republic of Benin, prepared by the National Fund of Social Security (CNSS) do not reflect the reality of the facts. Statistical data on professional illnesses indicate that only 16 cases are declared and covered by the social security scheme in force. The other occupational health indicators such as occupational accident frequency and severity rates, lost working days by industry are not always available.

According to Bakker and al. (2008) [8], people suffering from psychological distress at work have anxious and depressive reactions. They are irritable and have difficulty concentrating or performing complex tasks. They have sleep disorders, are frequently absent or are victims of presenteeism. At the MESRS, the grievances and claims of the social partners are focused on the working conditions of the staff, the equipment and commissioning of a nursing service, the litigation related to personnel management. The absence of monitoring indicators on workers' health in Benin shows that an approach to the exploration of psychosocial risks that are prohibitive to the psychological well-being of the professional world in a crisis of vulnerability is needed. The purpose of this study is to evaluate the mental state of the workers of the Ministry of Higher Education and Scientific Research (MESRS) in Benin.

\section{Methodology}

The MESRS served as the institutional framework for the study. Its area of expertise is broad and comes down to the design, development, and management of general policies and programs of research, teaching, training as well as their implementation in public and private institutions in the sector of higher education (Decree No. 2016-419 of 20 July 2016 on the Assignments, Organization and Functioning of the Ministry of Higher Education and Scientific Research). The operation of the MESRS is subdivided into two interdependent components, one political and the other administrative. For the good functioning of the Ministry, several structures are attached to it. They are the Minister's Office; the structures of the central administration (the general inspection of the Ministry, the general secretariat of the Ministry, the central directions, the general directions, the technical directions); public bodies and institutions under supervision (national universities, research centers and agencies, etc.); advisory and / or deliberative bodies. These structures are spread over the entire national territory and are changing according to the reforms and the development policy of this sector. These institutional mutations and instabilities are not without consequences on the people who are in charge of animating them. In fact, each modification leads to changes in staff, job cuts, role and assignment conflicts, and psychological repercussions.

The human resources of the MESRS include three types of personnel: the research staff, the university teaching staff and the administrative, technical and service staff. These three types of personnel are grouped into three body categories namely ACE (State Contract Agents), State Civil Servants/APE (State Permanent Agents), and contracted agents. To better understand the state of human resources of the MESRS, a breakdown according to certain statistical parameters has been made and reproduced in Table 1:

Table 1. Distribution of MESRS staff by type and status.

\begin{tabular}{|c|c|c|c|c|c|c|}
\hline \multirow{2}{*}{ TYPE OF STAFF } & \multicolumn{4}{|c|}{ STATUTES } & \multirow{2}{*}{ TOTAL } & \multirow{2}{*}{$\%$} \\
\hline & ACE & $\%$ & APE & $\%$ & & \\
\hline Administrative, Technical and Service Staff & 209 & 44 & 333 & 27 & 542 & 32 \\
\hline Research staff & 13 & 3 & 53 & 4 & 66 & 4 \\
\hline Doctoral level research staff & 1 & 0 & 3 & 1 & 4 & 0.2 \\
\hline University teaching staff & 250 & 53 & 841 & 68 & 1091 & 64 \\
\hline Total & 473 & 100 & 1230 & 100 & 1703 & 100 \\
\hline
\end{tabular}

In addition to these two categories of personnel, the necessity to satisfy the need for personnel in view of the requirements of the autonomous structures under supervision has given rise to a third category called the contracted agents.

The study is transversal, descriptive, analytically oriented. The sampling is non-probabilistic and for convenience and concerned the agents in positions in the directions and structures under the supervision of the MESRS who agreed to answer our questions. The selection of participants took place among the staff of the MESRS without distinction of age, category and specialty. In total, out of 1703 staff including 542 administrative staff, 70 researchers, and 1091 teachers in the
MESRS, 580 agents agreed to participate in the survey. But in the end, it is 348 people who actually answered the questionnaire, 07 agents are subjected to the interview and the systematic observation, 03 resource persons enlightened us on the methods of assumption of responsibility. This sample is subdivided into sectors (the staff of the Central Administration, the Research Centers and Agencies (CAR), the University of Abomey-Calavi (UAC), the University of Parakou (UP), the National University of Sciences, Techniques, Engineering, and Mathematics (UNSTIM), and the National University of Agriculture (UNA), in collective (the Contracted Agents, State Administrative Civil Servants, Teachers).. Dependent variables 
are health and its physical and psychic manifestations. The independent variables are socio-demographic factors, psychosocial and organizational factors. Search tools are documentation, SATIN scales, interview and observation. The results were processed and analyzed by the Excel software, and R. We conducted this research from October 2018 to March 2019 in the strictest respect of ethics. Given the constraints related to various hazards, we are aware that it has certain limitations. It is in view of all these precautions that we present the following results.

\section{Results}

\subsection{Characteristics of the Respondents}

Respondents in our survey have diverse socio-demographic characteristics. Out of 348 respondents, 144 (42.1\%) were female versus $198(57.9 \%)$ male. In the industry, the rate of respondents was as follows: UAC $24.4 \%$, Central Administration $24.1 \%$, UP $18.9 \%$, UNSTIM 12.9\%, CAR $10.3 \%$, and UNA $9.2 \%$. The group of teachers comes in first place with $35.2 \%$ of respondents followed by State administrative civil servants $33.5 \%$, and agents under contract $30.9 \%$. Agents aged 35 to 44 are the most represented 50\%, followed respectively by age groups of 45 to 54 years $20.87 \%$, 25 to 34 years $16.52 \%, 55$ years and over $27.83 \%$, and those under 25 years $4.35 \%$.

\subsection{The Perception of Health}

The perception of physical health is present among MESRS workers as follows:

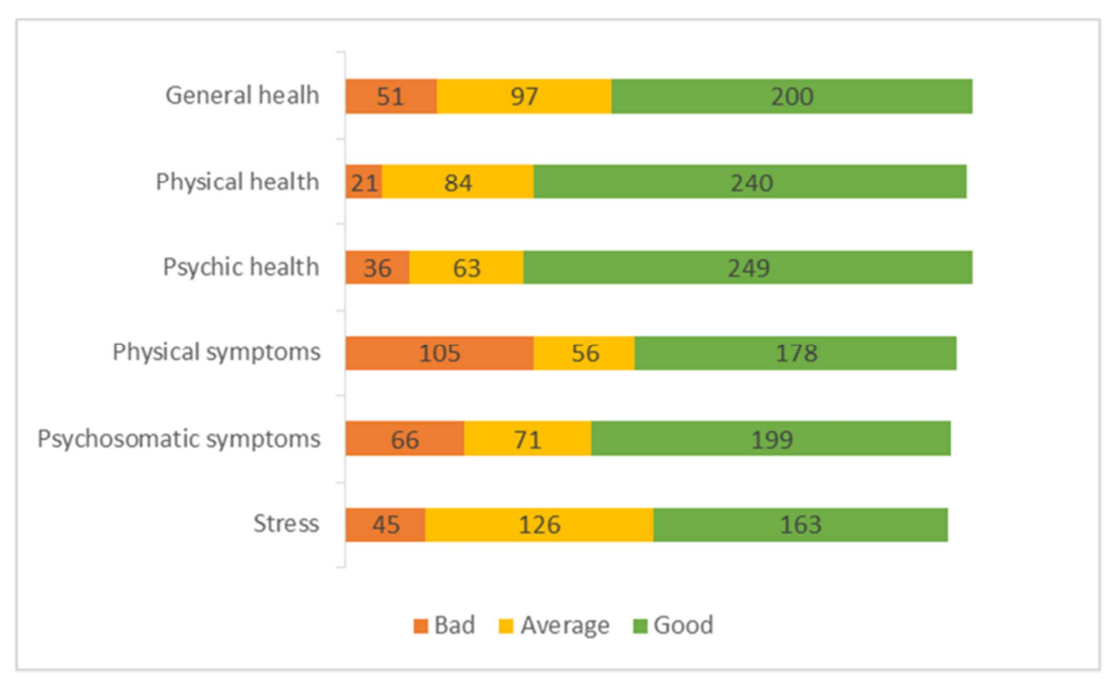

Figure 1. Health perceived globally.

\subsection{Work Environment at MESRS}

At MESRS, workers' perception of their environment is as follows:

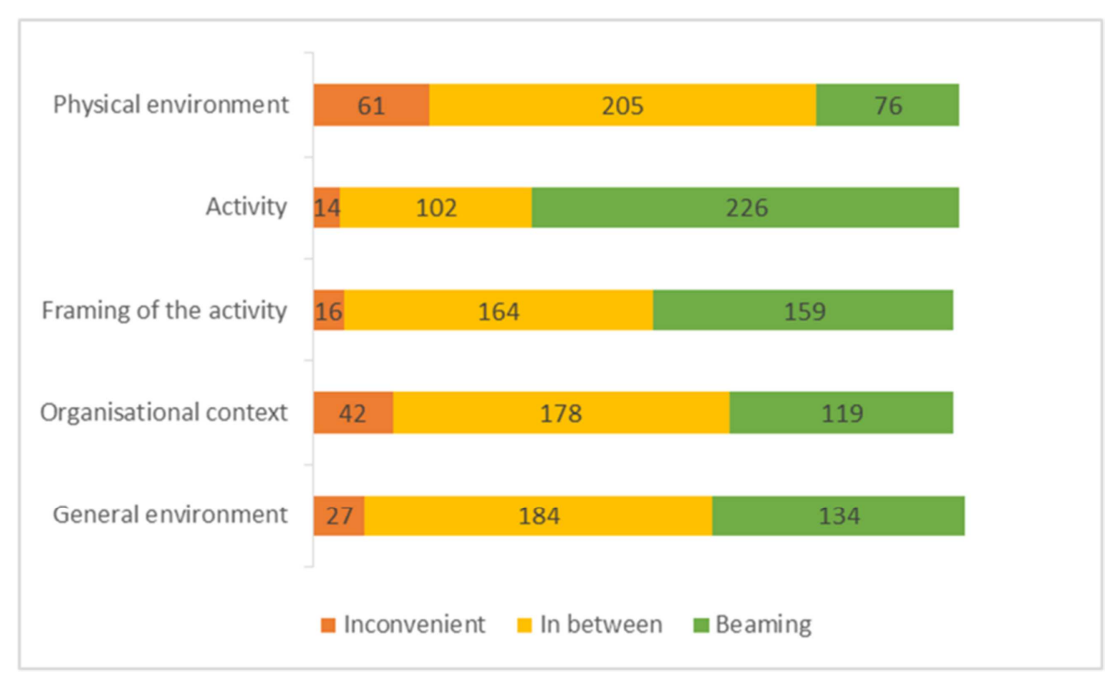

Figure 2. Work environment in three categories. 


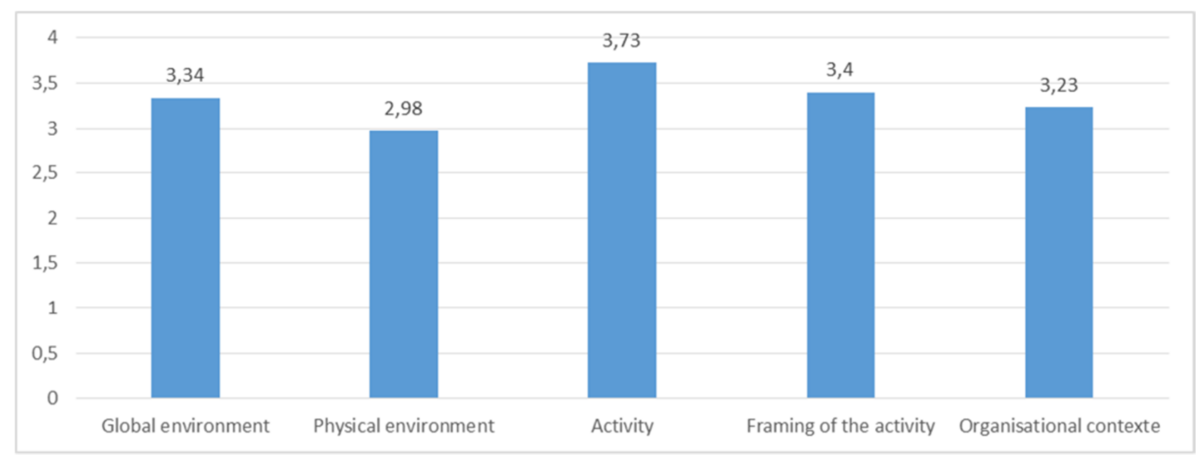

Figure 3. Work environment in average.

On a scale from 1 to 5 below $(1=$ Strongly upsets me, $2=$ Doesn'suit me, $3=I$ do with, $4=I$ agree, $5=$ Contribute to blooming), the components of the work environment, namely the global environment, the physical environment, the activity, the activity framing, and the organizational context are on average between I do with (3) and I agree (4) as shown in Figure 3 above.

The general appreciation of work and well-being in the institution is as follows:

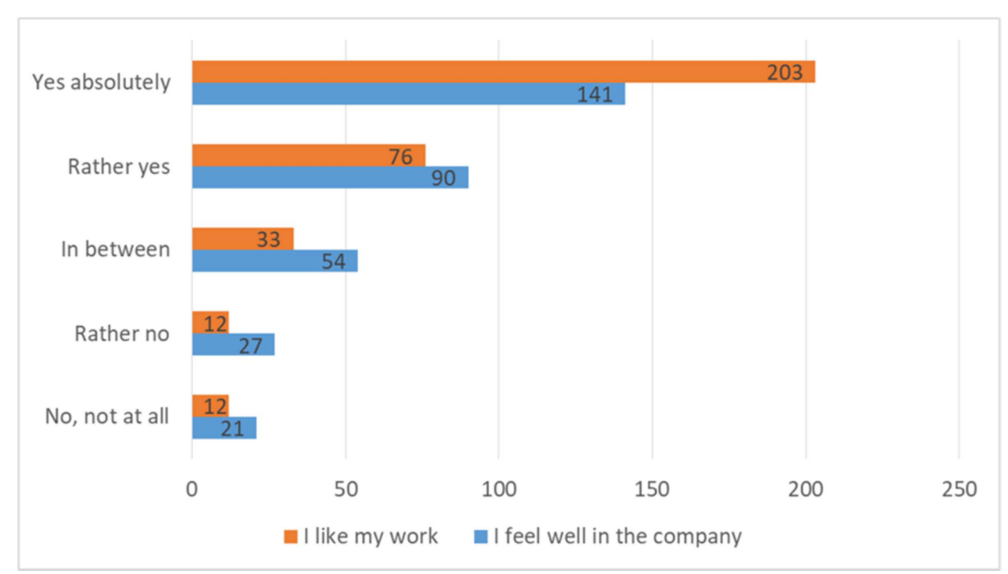

Figure 4. General appreciation of work.

\section{Discussion}

We did not compare the SATIN results with other studies, standards, references or calibrations the main function of which is to locate the individual responses of a person or a group of people compared to those of comparable people (from the point of view of age, gender, professional category...) at the risk of making a use of it contrary to the objectives that led to its creation. According to Grosjean and al (2017) [10], authors of SATIN, the "well-being approach..." which is at the origin of the SATIN tool "... is not compatible with this normative logic". For Grosjean and al [10], "Comparing the results of an employee or a group of employees to those of employees of other companies, the risk is great to adopt a normative logic intended to consider that" finally, the situation is not so bad. And so prevention priorities are not so urgent. "

In our study, general health was poor in $14.7 \%$ of subjects, average in $27.9 \%$, and good in $57.5 \%$. This result expresses the spirit of the obsolescence in which the workers (suffering in their flesh) live. Evidently, "a sane man is a patient who does not know himself", and the law of the labor code in Benin only recognizes the active expression of the occupational disease. Concerning mental health, it is bad in $10.3 \%$ of the subjects, average in $18.1 \%$, good in $1.6 \%$ ), and physical health is poor in $6.1 \%$ of subjects, average in $24.4 \%$, and good in $69.6 \%$. According to a study conducted in 2016 on the vulnerability to mental disorders, in the population of MESRS administrative staff in Benin using GHQ12 (General Heath questionnaire 12), 59\% reached the threshold of psychiatric disorder including 29\% threshold of prediction of cases, with $41 \%$ of social dysfunction [11]. Similarly, for overall perceived health, stress is poor at $13.5 \%$, average at $37.7 \%$, and good at $48.8 \%$. Psychosomatic symptoms are bad in $19.6 \%$ of subjects, average in $21.1 \%$, and good in $59.2 \%$. The physical symptoms are bad at $31.0 \%$, average for $16.5 \%$, and good for $52.5 \%$. According to a 2016 study on vulnerability to mental disorders, in the MESRS administrative population in Benin using GHQ12 (General Heath questionnaire 12 ), on the depression / anxiety subscale, $29 \%$ reported an attack of symptoms of depression and anxiety [11]. Although the measuring instruments are different, they all collected significant frequencies of reaching the psychic dimensions. These results confirm a worrying existence of mental health risks in the MESRS. Added to this is the physical and organizational environment that is variously appreciated, annoying and unsuitable for some workers. Thus, the solution would only be an 
emergence of managerial will to improve the organizational context of work at MESRS, taking into account the factors of reinforcement of the human capital.

The World Health Organization (WHO, 2014) [12] defines mental health as "a state of well-being in which the individual realizes his or her own abilities, can cope with the ordinary tensions of life, and is able to contribute to his community." This WHO's definition shows that psychological well-being is influenced by certain determinants such as the psychic characteristics or resources of the individual, the socio-economic context in which he finds himself, and his life environment. Various researches on psychological distress in the workplace highlights some of the factors that can influence mental health and psychological well-being. Hayasaka et al. (2007) [13] emphasized that the physical work environment, such as temperature, dust, lighting, ventilation, and vibration, promotes the emergence of psychological distress. Wilkins and Beaudet, (1998) [14] in their study argue that the unpleasant work environment increases the appearance of psychological distress among workers. Other studies mention that atypical hours and hours of work can also affect the mental health of workers. Indeed, Marchand and al. (2003) [15] revealed in their study that an irregular work schedule and long working hours favored the onset of psychological distress. For Ala-Mursula and al. (2006) [16], overtime during working hours increases the rate of absence of disease. Shigemi and al. (1997) [17] show that a too competitive mind, high responsibilities, the pressure of time and too long working hours contribute to psychological distress.

\section{Conclusion}

The study reveals that health at work includes different components. On the positive side, it manifests itself in the psychological well-being and happiness of the workers. On the negative side, health at work may be affected by psychological distress and its consequences. The physical and psychological health, the work environment, the context of the activity, and the organizational context as perceived by the workers of the MESRS, show the state of obsolescence of psychological well-being in which they live. However, we must distinguish the psychological distress of these agents from their burnout. Psychological distress does not necessarily imply burnout although there is a cause and effect relationship. But the neglect of the psychological distress among MESRS workers is a risk that may evolve towards the deterioration of their psychological well-being, and their mental health. A preventive approach including the reinforcement of the human capital, a better organization of the work, and the improvement of the working conditions will contribute to mental well-being and good job performance. Therefore, a prompt action from the authorities in charge of the ministry is highly desirable.

\section{References}

[1] Paine WS (1984). Professional burnout: Some major costs. Family \& Community Health, vol. 6, n 4 , p. 1-11.
[2] Leiter MP, Maslach C (2005). Banishing Burnout: Six Strategies for Improving Your Relationship with Work. San Francisco: Jossey Bass, 196 p.

[3] International Labor Office (1993). « Le travail dans le monde-Chapitre 5: le stress dans le monde du travail » BIT, Genève.

[4] Sahler B, Berthet M, Douillet P, Mary-Cheray I (2007). « Prévenir le stress et les risques psychosociaux au travail ». Anact, Lyon.

[5] OCDE (2012). "Mal-être au travail? Mythes et réalités sur la santé mentale et l'emploi", Santé mentale et travail. Rapport. www.oecd.org.health.

[6] Hassard J, Teoh K, Cox T, Dewe P, Cosmar M, Gründler R, Flemming D, Cosemans B, et Van den Broek K (2014). Calcul des coûts du stress et des risques psychosociaux liés au travail Analyse documentaire. Agence européenne pour la sécurité et la santé au travail; Observatoire européen des risques (EU-OSHA.), ISSN: 1831-9351, 6-11.

[7] WASHEQ (2015). Les indicateurs de la sécurité et la santé au travail en République du Bénin (Suru-Léré/Lagos).

[8] Bakker A (2008). How job demands, resources and burnout predict objective performance: A constructive replication. Anxiety, stress and coping, vol. 21, n³, 309-324.

[9] Decree No. 2016-419 of 20 July 2016 on the assignment, organization and functioning of the Ministry of Higher Education and Scientific Research.

[10] Grosjean V, Kop JL, Formet-Robert N, Althaus V (2017). SATIN version 3.0: Un questionnaire d'évaluation de la santé et du bien-être au travail pour la prévention, le diagnostic et l'intervention. Manuel d'Utilisation. INRS/NS 344.

[11] Eganhoui D (2015). Le syndrome d'épuisement professionnel chez le personnel administratif du MESRS au Bénin. Mémoire de Master, Psychologie, UAC/Bénin.

[12] OMS (2014). La santé mentale: renforcer notre action, Aide-mémoire $\mathrm{N}^{\circ} 220$.

[13] Hayasaka T, Satake S, Shimizu A, Sugimoto N, Matsui I, Aoki K, Muraji Y (2007). The vertical distribution and optical properties of aerosols observed over Japan during ABCEAREX2005. J. Geophys. Res. 112. (reviewed).

[14] Wilkins K, Beaudet MP (1998). Work stress and health. Health Rep. Winter; vol. 10, n³, p. 47-62.

[15] Marchand A, Demers A, Durand P, Simard M (2003). Occupational variations in drinking and psychological distress: A multilevel analysis. Work: Journal of Prevention, Assessment \& Rehabilitation, vol. 21, 153-163.

[16] Ala-Mursula L, Vahtera J, Kouvonen A, Pentti J, Kivimäki M (2006). Long hours in paid and domestic work and subsequent sickness absence: Does control over daily working hours matter? Occupational and Environmental Medicine.

[17] Shigemi J, Mino Y, Tsuda T. Babazono A (1997). The Relationship between Job Stress and Mental Health at Work. in Industrial Health, vol. 35, ${ }^{\circ} 1,29-35$. 